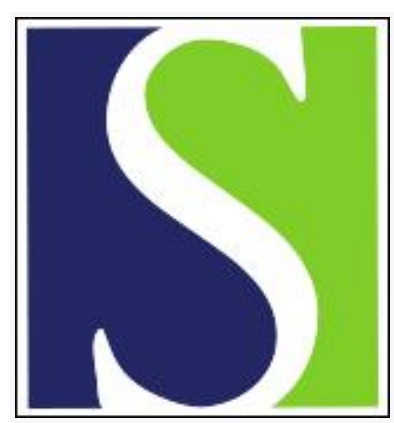

Scand J Work Environ Health 1996;22(1):27-34

https://doi.org/10.5271/sjweh.105

Issue date: Feb 1996

\title{
Mortality in a cohort of Russian fertilizer workers
}

by Bulbulyan MA, Jourenkova NJ, Boffetta P, Astashevsky SV, Mukeria $A F$, Zaridze DG

Key terms: arsenic; lung cancer; nitrogen oxide; stomach cancer

This article in PubMed: www.ncbi.nlm.nih.gov/pubmed/8685670

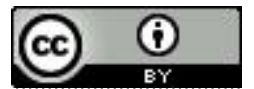




\title{
Mortality in a cohort of Russian fertilizer workers
}

\author{
by Mariana A Bulbulyan, DSc, ${ }^{1}$ Nadejda J Jourenkova, $M D,{ }^{1,2}$ Paolo Boffetta, $M D{ }^{2}$ \\ Sergey V Astashevsky, BSc, ${ }^{1}$ Anush F Mukeria, MD, ${ }^{1}$ David G Zaridze, DSC ${ }^{1}$
}

\begin{abstract}
Bulbulyan MA, Jourenkova NJ, Boffetta P, Astashevsky SV, Mukeria AF, Zaridze DG. Mortality in a cohort of Russian fertilizer workers. Scand J Work Environ Health 1996;22:27-33.
\end{abstract}

\begin{abstract}
Objectives The study evaluated the mortality of workers exposed to precursors of $\mathrm{N}$-nitroso compounds in a Russian fertilizer plant.

Methods Workers employed at least two years between 1945 and 1985 in production departments or other services were included in the cohort, which comprised 2039 men and 2957 women followed from 1965 to 1990. The standardized mortality ratios (SMR) were calculated using cause-specific death rates for the Moscow region as reference. An internal comparison was carried out using Poisson regression modeling. Exposure to arsenic, nitrogen oxides, and sulfur dioxide was estimated from an industrial hygiene survey.

Results The production and other workers had no excess of mortality from all causes or all neoplasms. However the male production workers had excess mortality from all cancers combined (SMR 143) and lung cancer (SMR 186) after a latency period of $\geq 20$ years. Men with the highest exposure to nitrogen oxides had a twofold increase in mortality from stomach cancer, with a marginally significant increasing trend between stomach cancer and cumulative exposure to nitrogen oxides for both genders. Excess mortality from all cancers and stomach cancer was found for the workers with the highest average exposure to arsenic, and excess lung cancer mortality could be attributed to exposure to arsenic.

Conclusions The investigation showed a weak association between employment in a fertilizer production plant and increased mortality from cancer. The results somewhat support the hypothesis that occupational exposure to precursors of $\mathrm{N}$-nitroso compounds increases the risk of stomach cancer mortality, as does exposure to arsenic.
\end{abstract}

Key terms arsenic, lung cancer, nitrogen oxides, stomach cancer.

It is known that carcinogenic $\mathrm{N}$-nitroso compounds can be formed endogenously from noncarcinogenic nitrogen-containing precursors. Humans are exposed to a wide range of precursors of $\mathrm{N}$-nitroso compounds from different sources, in particular in the workplace (1).

Fertilizer workers are among the occupational groups exposed to precursors of $\mathrm{N}$-nitroso compounds. Fertilizer workers exposed to nitrates have been shown to have substantially higher concentrations of nitrates in saliva in comparison with unexposed workers (2). The results of several studies conducted among fertilizer workers exposed to large amounts of precursors of $\mathrm{N}$-nitroso compounds are contradictory. In a census-based mortality study conducted in the United Kingdom (3), a significant excess risk for all cancers was found in an analysis by frequency of dust exposure, but this result was not con- firmed in an analysis by product type. In another British study (2), a nonsignificant excess of lung cancer was found in the heavily exposed group. An excess risk of prostate cancer was found in a cohort of Swedish fertilizer workers; this increase was not enhanced by applying at least a 10-year latency period (4). Studies conducted in Norway and Iceland did not suggest any increase in the risk of cancer $(5-6)$.

This study was initiated to investigate possible adverse health effects in the form of excess mortality among workers exposed to precursors of carcinogenic N-nitroso compounds, especially nitrogen oxides, in a Russian plant producing strong inorganic acids (sulfuric, nitric, phosphoric) and nitrate-containing fertilizers. Strong inorganic acids were used as raw materials for the fertilizer manufacturing.

1 Department of Epidemiology and Prevention, Institute of Carcinogenesis, NN Blokhin Cancer Research Centre, Moscow, Russia.

Unit of Environmental Cancer Epidemiology, International Agency for Research on Cancer, Lyon, France.

Reprint requests to: Dr NJ Jourenkova, Unit of Environmental Cancer Epidemiology, International Agency for Research on Cancer, 150 cours Albert-Thomas, 69372 Lyon cedex 08, France. 
In addition, occupational exposure to chemicals such as strong inorganic acids, sulfur dioxide, fluorides, and arsenic was assessed.

\section{Subjects and methods}

The study was carried out in one of the largest Russian plants situated in the town of Voskresensk in the Moscow region. Exposure to nitrogen oxides or to other nitrogen compounds was encountered in six production departments: (i) sulfuric acid manufacture (tower process), (ii) sulfuric acid manufacture (contact process), (iii) ammonia manufacture, (iv) phosphoric acid manufacture, (v) nitric acid manufacture, and (vi) compound fertilizer production.

The tower process takes place in the oldest department manufacturing sulfuric acid. In the tower process sulfuric acid is formed by the reaction between sulfur dioxide and nitrosylsulfuric acid (sulfuric acid with nitrogen oxides dissolved in it). Nitrogen oxides released as a result of the reaction are reissued in the cycle. Until the end of 1975, sulfur dioxide was derived from pyrite containing some arsenic.

In the sulfuric acid manufacture with the contact process, sulfur dioxide is first converted to sulfur trioxide in a converter; then sulfur trioxide is dissolved in water to produce sulfuric acid.

In the ammonia manufacture, ammonia was synthesized from oxygen and nitrogen derived from air.

The phosphoric acid manufacture involves the production of phosphoric acid from phosphate rock treated with sulfuric acid and phosphoric acid successively. During the reaction fluoric compounds are released into workspace.

Nitric acid was manufactured by catalytic oxidation of ammonia in air.

During the production of the compound fertilizer, compound fertilizer consisting of ammonia nitrate, ammonia phosphate, and potassium chloride was produced.

An industrial hygiene survey was conducted with the participation of a local industrial hygienist. Descriptions of technological processes and interviews with departmental chiefs and safety officers were carried out. Exposure measurements had been made by the central laboratory of the plant since 1972. Standard methods adopted in the United Soviet Socialist Republic (USSR) were used (7). In the production departments the mean annual concentrations of nitrogen oxides ranged from 1.12 to $10.55 \mathrm{mg} \cdot \mathrm{m}^{-3}$. The mean annual concentrations of dust containing nitrates ranged from 2.37 to $4.43 \mathrm{mg} \cdot \mathrm{m}^{-3}$. Sulfur dioxide was found in concentrations from 1.57 to $16.22 \mathrm{mg} \cdot \mathrm{m}^{-3}$. Measurements of the substances under study were not conducted in all the departments; in particular, data on arsenic exposure were not available.
Therefore the direct use of exposure measurements was impossible in the analysis.

Exposure to the main agents (nitrogen oxides, sulfur dioxide, sulfuric acid mist, arsenic, fluoric compounds, and nitrate) was classified according to the industrial hygiene survey as low (score value 1), medium (score value 2), high (score value 3 ) for each department and for the auxiliary staff of the plant. As the production in all the departments was characterized by the absence of significant technological changes in the study period, the exposures to all pollutants except arsenic were assumed to be constant over time in the model. Individual cumulative exposures (in unit-years) were calculated on the basis of this classification as score values multiplied by duration of employment. Additional analyses were conducted using the weights of 1 (low), 10 (medium), and 50 (high).

Individual exposures within the departments were likely to be similar, since gases and dusts tended to spread throughout the departments from several sources during production and most of the workers did not stay within a single location during a workday.

Both the men and the women employed at least two years between 1945 and 1985 in the six departments included in the study, as well as auxiliary workers of the plant, workers of the central laboratory and office workers and technicians, were included in the cohort. Information on name, date of birth, gender, address, and date of starting and ending every job during employment at the plant was abstracted from the records of the Personnel Department.

The cohort was subdivided into the following two main groups: production workers, including those employed in the six departments, and other workers. The workplaces of the other workers were situated around the perimeter of the main plant.

The cohort, consisting of 2039 men and 2957 women, was followed until the end of 1990 . Records for all the members of the cohort were sent to the Central Address Bureau of Moscow City and Moscow Region to determine the vital status of the members of the cohort. Vital status records are maintained by the Address Bureau of Russia for a period of five years. The vital status of the workers who had been identified by the Address Bureau as not resident in the city or region of Moscow was checked in the State Registry Office files. Any persons untraced by these means were considered to be followed until the date of leaving the plant. The causes of death of the deceased members of the cohort were abstracted from the death certificates in local state registry offices. Certified causes of death were coded according to the International Classification of Diseases, ninth revision (ICD-9).

Standardized mortality ratios (SMR) for all cancers, cancers of the main sites, and other major causes of death were calculated with $95 \%$ confidence intervals 
(95\% CI) on the assumption of a Poisson distribution. Person-years at risk were accumulated by gender and five-year age categories. The gender- and age-specific mortality rates for the Moscow region were calculated for 1970,1979 , and each year from 1981 on. The 1970 rates were used to calculate the expected number of deaths during the period 1965-1974; the 1979 rates were used for $1975-1980$. Workers deceased before 1965 were excluded from the analysis. The analysis was conducted by department, latency period, duration of employment, and cumulative exposure. In the analysis by department those who worked in more than one department during their employment at the plant were included in the analysis by department.

Exposure response gradients for the main air pollutants were examined by means of internal rate comparisons using Poisson regression modeling (8). Relative risks (RR) adjusted for age (four levels: <45, 45-54, $55-64, \geq 65$ years), calendar year (four levels: before $1975,1975-1979,1980-1984$, after 1985) and gender were estimated for cumulative exposure to nitrogen oxides, sulfur dioxide and arsenic, for average exposure to the same substances, and for duration of employment. The RR values have been expressed with the rates in the lowest exposure or duration categories as the reference. Person-years were tabulated using a program described by Pearce \& Checkoway (9). The statistical package GLIM was used for the Poisson regression analysis (10). Different approaches to person-years approximation for the SMR and Poisson regression analyses led to minor differences in the number of person-years and deaths in the different strata.

\section{Results}

The cohort consisting of 2039 men and 2957 women contributed 84193 person-years during 1965-1990; 320 persons ( 86 production workers and 234 other workers) were lost to follow-up.

Mortality from all causes combined among the production workers of both genders was slightly decreased when compared with the reference rates (305 deaths, SMR 94, 95\% CI 84-105). The overall mortality of other workers was significantly decreased (632 deaths, SMR 91, 95\% CI 84-98). These results were mainly due to a significant deficit of deaths from circulatory diseases among the production workers (107 deaths, SMR 78, 95\% CI 64-95) and other workers (309 deaths, SMR $82,95 \%$ CI 73-92). The number of deaths from all malignancies among the production workers was close to the expected number ( 77 deaths, SMR 101, 95\% CI $80-126)$, but for the other workers it was less than expected (147 deaths, SMR 90, 95\% CI 75-105). For the category of injury and poisoning the number of deaths was significantly higher than expected for both groups (73 deaths, SMR 170, 95\% CI 133-214, and 74 deaths, SMR 145, 95\% CI 114-182, respectively).

For the male production workers (table 1) there was an excess risk of death from all malignant neoplasms (SMR 143, 95\% CI 103-192) and lung cancer (SMR $186,95 \%$ CI 108-297) after a latency period of 20 years or more was applied. No increase was noticed for other male workers. There were three deaths from cancer of the larynx (one death among the production workers and two among the other workers), but the SMR was not calculated since the reference rates were not available. For the women, no excess mortality was found among either the production workers or the other workers except for a nonsignificant excess of lung cancer among the production workers, but this result was based on three deaths (table 2).

In the analysis by department slightly increased SMR values were found mainly for the workers in the sulfuric acid department (tower process) for all cancers (32 deaths, SMR 121, 95\% CI 83-171), for stomach cancer

Table 1. Mortality from all causes and from cancer of selected sites in male workers. $(0=$ observed number of deaths, SMR $=$ standardized mortality ratio, $95 \% \mathrm{Cl}=95 \%$ confidence interval)

\begin{tabular}{|c|c|c|c|c|c|c|}
\hline \multirow[t]{2}{*}{ Cause of death ${ }^{a}$} & \multicolumn{3}{|c|}{ Total group } & \multicolumn{3}{|c|}{$\geq 20$-year latency } \\
\hline & 0 & SMR & $95 \% \mathrm{Cl}$ & 0 & SMR & $95 \% \mathrm{Cl}$ \\
\hline \multicolumn{7}{|l|}{ Production workers ${ }^{b}$} \\
\hline $\begin{array}{l}\text { All causes (001-999) } \\
\text { All malignant neoplasms }(140-208)\end{array}$ & $\begin{array}{r}223 \\
59\end{array}$ & $\begin{array}{r}95 \\
113\end{array}$ & $\begin{array}{l}83-108 \\
86-146\end{array}$ & $\begin{array}{r}123 \\
43\end{array}$ & $\begin{array}{l}105 \\
143\end{array}$ & $\begin{array}{r}87-125 \\
103-192\end{array}$ \\
\hline $\begin{array}{l}\text { Stomach (151) } \\
\text { Lung }(162)\end{array}$ & $\begin{array}{l}19 \\
19\end{array}$ & $\begin{array}{l}124 \\
124\end{array}$ & $\begin{array}{l}74-193 \\
75-194\end{array}$ & $\begin{array}{l}12 \\
17\end{array}$ & $\begin{array}{l}137 \\
186\end{array}$ & $\begin{array}{r}71-239 \\
108-297\end{array}$ \\
\hline \multicolumn{7}{|l|}{ Other workers } \\
\hline $\begin{array}{l}\text { All causes (001-999) } \\
\text { All malignant neoplasms }(140-208)\end{array}$ & $\begin{array}{r}298 \\
54\end{array}$ & $\begin{array}{l}98 \\
76\end{array}$ & $\begin{array}{l}87-110 \\
57-100\end{array}$ & $\begin{array}{r}116 \\
24\end{array}$ & $\begin{array}{r}103 \\
87\end{array}$ & $\begin{array}{l}85-124 \\
56-129\end{array}$ \\
\hline $\begin{array}{l}\text { Stomach (151) } \\
\text { Lung (162) }\end{array}$ & $\begin{array}{l}18 \\
20\end{array}$ & $\begin{array}{l}86 \\
97\end{array}$ & $\begin{array}{l}51-136 \\
59-149\end{array}$ & $\begin{array}{r}10 \\
6\end{array}$ & $\begin{array}{r}127 \\
73\end{array}$ & $\begin{array}{l}61-233 \\
27-159\end{array}$ \\
\hline
\end{tabular}

a International Classification of Diseases, ninth revision, in parentheses.

b Total group $=1120$ subjects, 17905.3 person-years; group with 20 -year latency period $=542$ subjects, 3948.7 person-years.

- Total group $=919$ subjects, 14157.3 person-years; group with 20-year latency period $=433$ subjects, 3293.4 person-years. 
Table 2. Mortality from all causes and from cancer of the main sites in the female workers. $(0=0$ observed number of deaths, $\mathrm{SMR}=$ standardized mortality ratio, $95 \% \mathrm{Cl}=95 \%$ confidence interval)

\begin{tabular}{|c|c|c|c|c|c|c|}
\hline \multirow[t]{2}{*}{ Cause of deatha } & \multicolumn{3}{|c|}{ Total group } & \multicolumn{3}{|c|}{$\geq 20$-year latency } \\
\hline & 0 & SMR & $95 \% \mathrm{Cl}$ & 0 & SMR & $95 \% \mathrm{Cl}$ \\
\hline \multicolumn{7}{|l|}{ Production workers } \\
\hline $\begin{array}{l}\text { All causes }(001-999) \\
\text { All malignant neoplasms }(140-208)\end{array}$ & $\begin{array}{l}82 \\
18\end{array}$ & $\begin{array}{l}92 \\
75\end{array}$ & $\begin{array}{l}73-114 \\
45-119\end{array}$ & $\begin{array}{r}51 \\
9\end{array}$ & $\begin{array}{l}88 \\
64\end{array}$ & $\begin{array}{l}66-116 \\
29-121\end{array}$ \\
\hline $\begin{array}{l}\text { Stomach (151) } \\
\text { Lung (162) }\end{array}$ & $\begin{array}{l}5 \\
3\end{array}$ & $\begin{array}{r}81 \\
209\end{array}$ & $\begin{array}{l}26-188 \\
43-610\end{array}$ & $\begin{array}{l}3 \\
2\end{array}$ & $\begin{array}{r}77 \\
214\end{array}$ & $\begin{array}{l}16-224 \\
26-773\end{array}$ \\
\hline \multicolumn{7}{|l|}{ Other workers ${ }^{c}$} \\
\hline $\begin{array}{l}\text { All causes }(001-999) \\
\text { All malignant neoplasms }(140-208)\end{array}$ & $\begin{array}{r}334 \\
93\end{array}$ & $\begin{array}{r}86 \\
100\end{array}$ & $\begin{array}{l}77-96 \\
75-129\end{array}$ & $\begin{array}{r}183 \\
42\end{array}$ & $\begin{array}{l}86 \\
91\end{array}$ & $\begin{array}{l}73-98 \\
66-123\end{array}$ \\
\hline $\begin{array}{l}\text { Stomach (151) } \\
\text { Lung (162) }\end{array}$ & $\begin{array}{r}32 \\
5\end{array}$ & $\begin{array}{r}122 \\
84\end{array}$ & $\begin{array}{l}83-172 \\
27-197\end{array}$ & $\begin{array}{r}12 \\
1\end{array}$ & $\begin{array}{l}91 \\
32\end{array}$ & $\begin{array}{r}47-160 \\
1-178\end{array}$ \\
\hline
\end{tabular}

a International Classification of Diseases, ninth revision, in parentheses.

b Total group $=798$ subjects, 13829.4 person-years; group with 20 -year latency period $=412$ subjects, 3867.2 person-years.

c Total group $=2159$ subjects, 38300.7 person-years; group with 20-year latency period $=1216$ subjects, 10762.5 person-years

(13 deaths, SMR 169, 95\% CI 90-289), and for lung cancer (11 deaths, SMR 186, 95\% CI 93-334). These results were due to an excess of cancer mortality among the men of this department ( 27 deaths from all cancers, SMR 151, 95\% CI 100-220; 11 deaths from stomach cancer, SMR 204, 95\% CI 102-366; 10 deaths from lung cancer, SMR $187,95 \%$ CI 90-344). Only four deaths from cancer (SMR 52, 95\% CI 14-132) were found for the workers in the compound fertilizer department. Among these workers the number of deaths from stomach cancer ( 2 observed deaths) was close to the expected number (SMR 101, 95\% CI 12-365).

The analysis by duration of employment among either the production workers or the other workers did not reveal any significant excesses, although there was a marginally significant trend $(P=0.08$, based on four categories) for stomach cancer in the group of production workers (SMR 177, 95\% CI 57-412) with duration of employment of 20 years or more].

The initial analysis by cumulative exposure was conducted separately for the men and the women, using a subdivision of the cumulative exposure levels into two categories. This analysis showed an excess of death from stomach cancer for the men when the cumulative expo- sure to nitrogen oxides exceeded 40 unit-years ( 8 deaths, SMR 204, 95\% CI 102-365). The analysis by cumulative exposure to arsenic showed an excess risk of death from all neoplasms when the cumulative exposure was higher than 20 unit-years (36 deaths, SMR 144, 95\% CI 101-199). No significant results were found for the other substances of interest, including sulfuric acid mist, either for the men or the women (detailed results not presented). An analysis by cumulative exposure to nitrate was not conducted, as the number of exposed cases was too small.

A more-detailed analysis by cumulative exposure for both genders was conducted. It was restricted to nitrogen oxides, sulfur dioxide, and arsenic. The significant findings were an excess mortality from lung cancer when the cumulative exposure to arsenic was between 20 and 34 unit-years (SMR 260, 95\% CI 105-136) and a positive trend $(\mathrm{P}=0.03)$ for all neoplasms in the analysis by cumulative exposure to arsenic.

In the Poisson regression analysis (table 3 ) there was no indication of an increase in risk of death from neoplasms with increasing duration of employment, except for a marginally significant trend for stomach cancer $(\mathrm{P}=0.10)$.

Table 3. Mortality by duration of employment - Poisson regression analysis. The model was adjusted for age, gender, and calendar year. ( $0=$ observed number of deaths, $\mathrm{RR}=$ relative risk, $95 \% \mathrm{Cl}=95 \%$ confidence interval)

\begin{tabular}{|c|c|c|c|c|c|c|c|c|c|}
\hline \multirow[t]{3}{*}{ Duration of employment } & \multicolumn{9}{|c|}{ Cause of death ${ }^{\mathrm{a}}$} \\
\hline & \multicolumn{3}{|c|}{ All cancers $(140-208)$} & \multicolumn{3}{|c|}{ Stomach cancer (151) } & \multicolumn{3}{|c|}{ Lung cancer (162) } \\
\hline & 0 & $\mathrm{RR}$ & $95 \% \mathrm{Cl}$ & 0 & $\mathrm{RR}$ & $95 \% \mathrm{Cl}$ & 0 & RR & $95 \% \mathrm{Cl}$ \\
\hline $\begin{array}{l}2-4 \text { years } \\
5-9 \text { years } \\
10-19 \text { years } \\
\geq 20 \text { years }\end{array}$ & $\begin{array}{l}49 \\
40 \\
82 \\
53\end{array}$ & $\begin{array}{c}1.00 \\
0.78 \\
1.12 \\
1.08 \\
P=0.34 \mathrm{~b}\end{array}$ & $\begin{array}{c}-51-1.19 \\
0.79-1.60 \\
0.73-1.60\end{array}$ & $\begin{array}{l}13 \\
12 \\
32 \\
17\end{array}$ & $\begin{array}{c}1.00 \\
0.88 \\
1.68 \\
1.46 \\
P=0.10^{b}\end{array}$ & $\begin{array}{c}- \\
0.40-1.93 \\
0.88-3.21 \\
0.70-3.05\end{array}$ & $\begin{array}{r}15 \\
6 \\
19 \\
7\end{array}$ & $\begin{array}{c}1.00 \\
0.42 \\
0.90 \\
0.47 \\
P=0.29^{\circ}\end{array}$ & $\begin{array}{c}- \\
0.16-1.09 \\
0.46-1.78 \\
0.19-1.17\end{array}$ \\
\hline
\end{tabular}

a International Classification of Diseases, ninth revision, in parentheses.

b Test for linear trend. 
In the analysis by average exposure, excess risks for death from all cancers combined (35 deaths, RR 1.47, 95\% CI 1.01-2.13) and from stomach cancer (14 deaths, RR 1.82 , 95\% CI 1.01-3.29) were shown in the "3unit" exposure category for arsenic. There was a slight tendency towards increasing mortality from lung cancer with average exposure to arsenic, though the results were not significant. Mortality from stomach cancer was increased in the " $\geq 2$-units" category of average exposure to nitrogen oxides (1-unit category: 52 deaths, RR 1.00; 1.1 - to 1.9 -unit category: 10 deaths, RR $0.72,95 \% \mathrm{CI}$ $0.36-1.43 ; \geq 2$-unit category: 12 deaths, RR $1.85,95 \%$ CI $0.98-3.51$ ).

The only significant finding in the analysis by cumulative exposure (table 4) was the high relative risk of lung cancer in the category 20-34 unit-years of arsenic exposure ( 7 cases, RR $2.80,95 \%$ CI $1.21-6.46$ ), but the $\mathrm{RR}$ values did not increase in the category $35-49$ and $\geq 50$ unit-years. The RR values for stomach cancer tended to increase with the levels of cumulative exposure to nitrogen oxides and to sulfur dioxide, but the results lacked significance (tests for linear trend: $\mathrm{P}=0.08$ and $P=0.07$, respectively). Similar results were shown after different weights were used.

\section{Discussion}

This study was carried out with the main purpose of investigating whether occupational exposure to precur- sors of $\mathrm{N}$-nitroso compounds increases cancer mortality. A twofold increase in mortality from stomach cancer risk was found only for the men, when cumulative exposure to nitrogen oxides was $\geq 40$ unit-years. In addition, there was a marginally significant linear trend for stomach cancer in the Poisson regression analysis by cumulative exposure to nitrogen oxides.

Trace rates were higher for the production workers in comparison with the other workers. Although the same follow-up procedure was implemented for both groups, the follow-up of nonproduction workers was complicated by the fact that the members of the group seemed to be more mobile. As the occupations of these workers were less specialized than those of the production workers, it was easier for them to move out of the Moscow region, where they were not traced.

Low mortality from all causes combined and circulatory diseases is characteristic of industrial cohorts and can be considered a manifestation of the "healthy worker effect." Preemployment and periodic health examinations were performed in the plant. High mortality from injury and poisoning among the members of the cohort was found to be associated with work-related hazards and more in general with their low socioeconomic status.

The main limitation of the study was the absence of quantitative hygiene data spanning all the time periods and work areas. Insufficient exposure data precluded direct use in the dose-response analysis. The exposure scores were based on industrial hygiene judgments of differences in exposure between different work areas

Table 4. Mortality by cumulative exposure to the main air pollutants - Poisson regression analysis. The model was adjusted for age, gender, and calendar year. $(0=$ observed number of deaths, $\mathrm{RR}=$ relative risk, $95 \% \mathrm{Cl}=95 \%$ confidence interval)

\begin{tabular}{|c|c|c|c|c|c|c|c|c|c|}
\hline \multirow[t]{3}{*}{ Cumulative exposure level } & \multicolumn{9}{|c|}{ Cause of deatha } \\
\hline & \multicolumn{3}{|c|}{ All cancers $(140-208)$} & \multicolumn{3}{|c|}{ Stomach cancer (151) } & \multicolumn{3}{|c|}{ Lung cancer (162) } \\
\hline & 0 & $\mathrm{RR}$ & $95 \% \mathrm{Cl}$ & 0 & $\mathrm{RR}$ & $95 \% \mathrm{Cl}$ & 0 & RR & $95 \% \mathrm{Cl}$ \\
\hline \multicolumn{10}{|l|}{ Nitrogen oxides } \\
\hline $\begin{array}{l}<5 \text { unit-years } \\
5-9 \text { unit-years } \\
10-24 \text { unit-years } \\
\geq 25 \text { unit-years }\end{array}$ & $\begin{array}{l}41 \\
38 \\
83 \\
62\end{array}$ & $\begin{array}{l}1.00 \\
0.82 \\
1.04 \\
1.21 \\
P=0.18^{\circ}\end{array}$ & $\begin{array}{l}- \\
0.52-1.27 \\
0.71-1.52 \\
0.81-1.81\end{array}$ & $\begin{array}{l}10 \\
13 \\
31 \\
20\end{array}$ & $\begin{array}{c}1.00 \\
1.14 \\
1.64 \\
1.77 \\
P=0.08^{\mathrm{b}}\end{array}$ & $\begin{array}{c}- \\
0.50-2.60 \\
0.80-3.34 \\
0.82-3.80\end{array}$ & $\begin{array}{r}11 \\
6 \\
17 \\
13\end{array}$ & $\begin{array}{c}1.00 \\
0.50 \\
0.88 \\
0.83 \\
P=0.98^{b}\end{array}$ & $\begin{array}{l}0.19-1.35 \\
0.41-1.87 \\
0.37-1.87\end{array}$ \\
\hline \multicolumn{10}{|l|}{ Sulfur dioxide } \\
\hline $\begin{array}{l}<5 \text { unit-years } \\
5-9 \text { unit-years } \\
10-24 \text { unit-years } \\
\geq 25 \text { unit-years }\end{array}$ & $\begin{array}{l}43 \\
36 \\
84 \\
61\end{array}$ & $\begin{array}{l}1.00 \\
0.77 \\
1.02 \\
1.23 \\
P=0.16^{\mathrm{b}}\end{array}$ & $\begin{array}{c}- \\
0.50-1.20 \\
0.71-1.48 \\
0.83-1.82\end{array}$ & $\begin{array}{l}12 \\
10 \\
32 \\
20\end{array}$ & $\begin{array}{c}1.00 \\
0.77 \\
1.44 \\
1.58 \\
P=0.07 \mathrm{~b}\end{array}$ & \begin{tabular}{l}
\multicolumn{1}{c}{-} \\
$0.33-1.78$ \\
$0.74-2.8$ \\
$0.77-3.26$
\end{tabular} & $\begin{array}{r}11 \\
6 \\
18 \\
12\end{array}$ & $\begin{array}{c}1.00 \\
0.54 \\
0.94 \\
0.84 \\
P=0.99 \mathrm{~b}\end{array}$ & $\begin{array}{c}- \\
0.20-1.45 \\
0.44-2.01 \\
0.37-1.93\end{array}$ \\
\hline \multicolumn{10}{|l|}{ Arsenic } \\
\hline $\begin{array}{l}\text { Unexposed } \\
\leq 19 \text { unit-years } \\
20-34 \text { unit-years } \\
35-49 \text { unit-years } \\
\geq 50 \text { unit-years }\end{array}$ & $\begin{array}{r}166 \\
13 \\
12 \\
15 \\
18\end{array}$ & $\begin{array}{c}1.00 \\
0.87 \\
1.03 \\
1.47 \\
1.47 \\
P=0.09 \mathrm{~b}\end{array}$ & $\begin{array}{c}- \\
0.49-1.52 \\
0.57-1.85 \\
0.86-2.51 \\
0.90-2.40\end{array}$ & $\begin{array}{r}55 \\
3 \\
3 \\
6 \\
7\end{array}$ & $\begin{array}{c}1.00 \\
0.60 \\
0.76 \\
1.7 \\
1.91 \\
P=0.14^{b}\end{array}$ & $\begin{array}{l}-19-1.86 \\
0.19-1.86 \\
0.24-2.44 \\
0.72-4.00 \\
0.86-4.24\end{array}$ & $\begin{array}{r}28 \\
6 \\
7 \\
2 \\
4\end{array}$ & $\begin{array}{c}1.00 \\
1.87 \\
2.80 \\
0.86 \\
1.44 \\
P=0.27^{\circ}\end{array}$ & $\begin{array}{c}-77-4.54 \\
1.21-6.46 \\
0.20-3.64 \\
0.50-4.15\end{array}$ \\
\hline
\end{tabular}

a International Classification of Diseases, ninth revision, in parentheses.

b Test for linear trend. 
and over time, but the errors in the scores would rather lead to an attenuation of the estimated dose response because of misclassification, which one would expect to be nondifferential with respect to health outcome (11).

The confounding effect of cigarette smoking on the results of the study cannot be ruled out because data on smoking status among the members of the cohort were not available. However the difference in the results between the production and other workers, who belonged to the same social class, and the positive results of the analyses by cumulative and average exposures prevent us from explaining the excess risk of lung cancer only as an effect of smoking. The absence of excess mortality from circulatory diseases and other smoking-related cancers also argues against significant confounding.

In the analysis by duration of employment, we failed to find a statistically significant increase in mortality among the workers with the longest duration of employment. The explanation may be that workers more sensitive to an occupational factor, in particular to irritants of the respiratory tract such as nitrogen dioxide and sulfur dioxide, tended to leave their jobs.

A possible explanation for the fact that the excess risk of cancer was only apparent for the men is that the men may have been hired into less hygienic jobs and therefore were more highly exposed.

There was no increase in the mortality from all cancers combined or lung cancer in conjunction with exposure to nitrogen oxides. However, we found an excess mortality from all cancers combined and lung cancer among the male production workers when a 20 -year latency period was applied. This excess indicates that an effect of occupational exposure cannot be dismissed.

Arsenic is a known human carcinogen, and occupational exposure to it has been associated with excess risk of lung cancer in several studies (12). In the present investigation a significant excess of lung cancer was observed for one of the cumulative exposure categories. In addition, a marginally significant trend was found in the analysis by average exposure $(P=0.07)$.

A nearly twofold excess risk of stomach cancer was shown for the heavily exposed group in the analysis by average exposure to arsenic. An excess mortality from stomach cancer has been observed for glass workers and gold miners; however, they were exposed to other potentially carcinogenic substances $(13,14)$. It should be pointed out that most of the deaths from stomach cancer were attributed to the workers of the sulfuric acid department (tower process), where the highest concentrations of nitrogen oxides were observed. In addition, a twofold increase in the risk of stomach cancer among men in the SMR analysis by cumulative exposure to nitrogen oxide and a positive trend in the Poisson regression analysis by cumulative exposure suggested the possibility that expo- sure to nitrogen oxides might increase the risk of gastric cancer.

The incidence of gastric cancer has been found to be inversely related to socioeconomic status (15), and it therefore probably reflects life-style factors. Previous studies among fertilizer workers failed to find any increase in gastric cancer (2-6). It is noteworthy that these earlier investigations were conducted in western European countries where stomach cancer rates are low in comparison with Russia's. Mortality from stomach cancer in the ex-USSR is 38.8 for men and 17.0 for women (per 100 000, world standard) (16). The incidence rates of stomach cancer in the USSR are among the highest recorded worldwide. The highest age-standardized incidence rates have been observed in Russia (17). The general assessment of vital registration data has been good on the whole (18). All deaths occurring in the ex-USSR are medically certified ( $94 \%$ by physicians, $6 \%$ by feldschers) (19).

It has been shown that an increased risk of stomach cancer is associated with dietary factors (20). The consumption of fresh fruit and vegetables is among the most obvious differences in the diet of Russian and western European populations. It is known that a western diet rich with fresh fruit and vegetables is related to a high intake of vitamins such as ascorbate, which reduces endogenous nitrozation (21). Several studies have shown an association between stomach cancer and infection with Helicobacter pylori (22) and also between stomach cancer and previous gastric surgery (23).

In conclusion, our investigation did not show a strong association between employment in fertilizer production and an increased risk of mortality from cancer. A possible exposure misclassification could have reduced the power of detecting the association. The fact that excess mortality from lung cancer was associated with average exposure to arsenic, but no significant trend was found in the analysis by cumulative exposure, confirms this suspicion. The results somewhat support the hypothesis that occupational exposure to precursors of N-nitroso compounds (in particular, to nitrogen oxides) increases the risk of stomach cancer. An increased mortality from stomach cancer in this cohort can be attributed to the exposure to arsenic as well, though these exposures were highly correlated. Additional investigations are needed to confirm the results of our study.

\section{Acknowledgments}

The research described in this publication was made possible by grant N M42000 from the International Science Foundation. The analysis for this study was undertaken during the tenure of a special training award of Dr 
NJ Jourenkova at the International Agency for Research on Cancer; the training award was partially supported by EEC BIOMED-1 grant (contract BMH1-CT92-1110).

We thank $\mathrm{Mr} G$ Ferro for his contribution to the statistical analysis and Dr T Partanen for his comments on the manuscript.

\section{References}

1. Preussmann R. Occurrence and exposure to N-nitrosocompounds and precursors. In: O'Neill IK, Von Borstel RC, Miller CT, Long J, Bartsch H, editors. N-nitrosocompounds: occurrence, biological effects and relevance to human cancer. Lyon: International Agency for Research on Cancer (IARC), 1984:3-15. IARC scientific publications, no 57.

2. Al-Dabbagh S, Forman D, Bryson D, Stratton I, Doll R. Mor* tality of nitrate fertilizer workers. Br J Ind Med 1986;43:50715.

3. Fraser $\mathrm{P}$, Chilvers C, Day M, Goldblatt P. Further results from a census based mortality study of fertilizer manufacturers. $\mathrm{Br} J$ Ind Med 1989;46:38-42.

4. Hagmar L, Bellander T, Andersson C, Linden K, Attewell R, Møller T. Cancer morbidity in nitrate fertilizer workers. Int Arch Occup Environ Health 1991;63:63-7.

5. Fandrem SI, Kyuus H, Andersen A, Amplie E. Incidence of cancer in a Norwegian nitrate fertilizer plant. $\mathrm{Br} \mathrm{J}$ Ind Med 1993;50:647-52.

6. Rafnsson V, Gunnarsdottir H. Mortality study of fertilizer manufacturers in Iceland. Br J Ind Med 1990;47:721 - 5.

7. Gidromemteoizdat. Rukovodstvo po kontrolu zagriaznenia atmosferi [Manual of atmosphere pollution control]. St Petersburg: Gidromemteoizdat, 1979.

8. Breslow NE, Day NE. Statistical methods in cancer research; vol II (The design and analysis of cohort studies). Lyon: International Agency for Research on Cancer (IARC), 1987. IARC scientific publications, no 82.

9. Pearce N, Checkoway H. A simple computer program for generating person-time data in cohort studies involving timerelated factors. Am J Epidemiol 1987;125:1085-91.

10. Payne CD. The GLIM system: release 3.77. Oxford: Numeri- cal Algorithms Group, 1985.

11. Rothman KJ. Modern epidemiology. Boston (MA): Little Brown, 1986.

12. International Agency for Research on Cancer (IARC). Overall evaluations of carcinogenicity: an updating of IARC monographs volumes 1 -42. Lyon: IARC, 1987. IARC monographs on the evaluation of carcinogenic risks to humans, suppl 7.

13. Wingren G, Axelson O. Mortality in the Swedish glasswork industry. Scand J Work Environ Health 1987;13:412 - 6 .

14. Kusiak RA, Ritchie AC, Springer J, Muller J. Mortality from stomach cancer in Ontario miners. Br J Ind Med 1993;50: $117-26$.

15. Cutler SJ, Young JL Jr, editors. Third national cancer survey: incidence data. NCI Monorg 1975;41.

16. Pisani $P$, Parkin DM, Ferlay $J$. Estimates of the worldwide mortality from eighteen major cancers in 1985: implications for prevention and projections of future burden. Int $\mathbf{J}$ Cancer 1993;55:891-903.

17. Zaridze D, Basieva T. Cancer incidence in the Commonwealth of Independent States, the Baltic states and Georgia the former USSR. Eur J Cancer 1993;29A:1609-20.

18. Anderson BA, Silver BD. The changing shape of Soviet mortality, 1958 - 1985: an evaluation of old and new evidence. Popul Stud 1989;43:243-65.

19. World Health Organization (WHO). World health statistics annual, 1991. Geneva: WHO, 1992.

20. Buiatti E, Palli D, Decarli A, Amadori D, Avellini C, Bianchi $S$, et al. A case-control study of gastric cancer and diet in Italy: II. association with nutrients. Int J Cancer 1990;45:896-901.

21. Forman D, Al-Dabbagh SA, Doll R. Nitrates, nitrites and gastric cancer in Great Britain. Nature 1985;313:620-5.

22. Correa P, Fox J, Fontham E, Ruiz B, Lin YP, Zavala D, et al. Helicobacter pylori and gastric carcinoma: serum antibody prevalence in populations with contrasting cancer risk. Cancer 1990;66:2569-74.

23. Tersmette AC, Offerhaus JA, Tersmette KWF, Giardiello FM, Moore GW, Tytgat GNJ, et al. Meta-analysis of the risk of gastric stump cancer: detection of high risk patients subsets for stomach cancer after remote partial gastrectomy for benign conditions. Cancer Res 1990;50:6484-9.

Received for publication: 20 February 1995 